\title{
Battling bullying: Do obese children face the same fight?
}

\section{Leigh Vanderloo and Gillian Mandich}

\section{Western University}

Over the past three decades, the prevalence of childhood overweight and obesity in Canada has nearly tripled. ${ }^{1}$ While the relationship between these chronic conditions and related physiological co-morbidities has been examined extensively, less attention has been focused on the psychological and social implications of increased adiposity. Given that obesity has been shown to serve as a determinant of mental health issues in childhood, ${ }^{2}$ additional attention is required. The following paper will address the impact of social stigmatization and discrimination, specifically bullying, on the psychological wellbeing of obese children, and will highlight potential solutions from a population health perspective.

\section{Overweight/obese children: A "bigger" target for bullying and mental illness?}

Obesity often lends way to overwhelming social calamity among children, with peer rejection being of particular note. ${ }^{2}$ Compared to their non-overweight counterparts, obese children have greater relative odds of being diagnosed with a psychiatric problem, ${ }^{3}$ and are at a marked risk for the development of mental health issues such as low self-esteem and poor body image. ${ }^{4,5}$ Higher rates of anxiety, depression, and eating disorders are common among this unique population. ${ }^{4}$

\section{Bullying among obese children: Adding more fuel to an already roaring fire}

Although bullying has been cited as a social repercussion of obesity, the degree of bullying is positively correlated with weight (i.e., the more overweight the child, the more intense the bullying episode). ${ }^{6}$ In fact, overweight and obese children are $10 \%$ and $60 \%$ more likely to be bullied than non-overweight and non-obese children, respectively. ${ }^{7}$
Even more alarming, obese children are at an increased risk for suicidal behaviours. Eaton and colleagues determined that weight-based teasing and victimization were positively associated with suicidal ideation and increased likelihood of suicide attempts among Caucasian, Hispanic, and Black students as compared to average-weight peers. ${ }^{8}$ This finding was further evidenced by Eisenberg and colleagues in 2003, as a sample of over 4,000 children who were teased about their weight were 2-3 times more likely to report suicidal ideation as compared to those who were not teased. ${ }^{9}$ Fortunately, there is also research to suggest that bullying and its associated suicide rates can be significantly reduced by implementing bullying education and prevention programs. In fact, children who participated in a suicide prevention program were $37 \%$ less likely to attempt suicide as compared to a control group. ${ }^{10}$

\section{Battling bullying: What can be done?}

Bullying is a complex social issue, and similar to obesity, there is no 'easy fix'; comprehensive interventions that include multiple sectors need to be considered. Interim steps should be taken to correct this pervasive form of social interaction. Specifically, because obese children are at increased risk of bullying, additional measures be it social skills development, curriculum, and/or school policies - should be taken to protect their social and mental wellbeing. Firstly, healthy relationships should be promoted at home and at school. Opportunities for positive relationship building for school-aged children can be achieved through presentations and hands-on workshops which focus on empathy, help-seeking behaviours, and problem solving and reporting skills. Secondly, negative stereotypes regarding obesity (e.g., obese people are lazy and/or unattractive, etc.) should be addressed. Given that bullying of obese children can be partially attributed to the 'other' children's negative associations with obesity, ${ }^{8}$ efforts should be made to correct these false perceptions. 
Lastly, parents and school officials play an important role in creating safe and healthy environments for children. If prosocial behaviours are displayed and encouraged by trusted authority figures, it is likely that children will mimic these actions and feel comfortable in seeking help. By working collaboratively to address bullying, thus decreasing the incidences that obese children are subjected to negative situations, we can strengthen our efforts in sheltering children from the unnecessary burden of mental health problems.

\section{Bullying: Future directions for promoting mental wellness among obese children}

Weight-based discrimination is as concerning as, for example, racial discrimination, gender discrimination, and/ or discrimination against children with physical disabilities. Addressing this issue is of equal importance for the purpose of protecting the emotional and physical well-being of our nation's children. Although more work is needed to better understand the extent to which stigma and teasing increase vulnerability to suicidal behaviours in obese youths, the current findings are sobering; they highlight the critical importance of studying the impact of stigmatizing experiences on the emotional well-being of this population as well as their effects on adverse psychosocial outcomes for obese children that may be exacerbated by weight bias. Like many health-related behaviours, mental health problems tend to persist throughout the lifespan if they are not addressed early. By means of promoting mental health wellness and pro-social behaviours among all young Canadians - inclusive of those who struggle with obesity we can strive to instill positive relational values in children as well as eradicate the weight-based stigma faced by obese children before it consumes their lives.

\section{References}

1. Shields M. Measured obesity: Overweight Canadian children and adolescents [internet]. Statistics Canada, Analytic Studies and Reports; 2005 [updated 2005 July 14; cited 2013 January 20]. Available from http:// www.statcan.gc.ca/pub/82-620-m/2005001/pdf/4193660-eng.pdf

2. Schwartz C, Waddell C, Barican J, Garland O, Nightingale L, Gray-Grant D. The mental health implications of childhood obesity. Children's Mental Health Research Quarterly. 2010; 4(1): 1-20. Vancouver, BC: Children's Health Policy Centre, Faculty of Health Sciences, Simon Fraser University.

3. Janicke DM, Harman JS, Kelleher KJ, Zhang J. Psychiatric diagnosis in children and adolescents with obesity-related health conditions. J Dev Behav Pediatr. 2008; 29: 276-284.

4. Bosch J, Stradmeijer M, Seidell J. Psychosocial characteristics of obese children/youngsters and their families: Implications for preventive and curative interventions. Patient Educ Couns. 2004; 55: 353-362.

5. Friedman MA, Brownell KD. Psychological correlates of obesity. Psychol Bul. 1995; 117: 3-20.

6. Janssen I, Craig WM, Boyce WF, Pickett W. Associations between overweight and obesity with bullying behaviors in school-aged children. Pediatrics. 2004; 113(5): 1187-1194.

7. Lumeng JC, Forrest P, Appugliese DP, Kaciroti N, Corwyn RF, Bradley RH. Weight status as a predictor of being bullied in third through sixth grades. Pediatrics. 2010; Jun; 125(6): e1301-1307.

8. Eaton DK, Lowry R, Brener ND, Galuska DA, \& Crosby AE. Associations of body mass index and perceived weight with suicide ideation and suicide attempts among US high school students. Arch Pediatr Adoles Med. 2005; 159: 513-519.

9. Eisenberg ME, Neumark-Sztainer D, \& Story M. Associations of weightbased teasing and emotional well-being among adolescents. Arch Pediatr Adoles Med. 2003; 157: 733-738.

10. Schwartz C, Waddell C, Barican J, Garland O, Nightingale L, \& Gray-Grant D. Preventing suicide in children and youth. Children's Mental Health Research Quarterly. 2009; 3(4): 1-24. Vancouver, BC: Children's Health Policy Centre, Faculty of Health Sciences, Simon Fraser University.

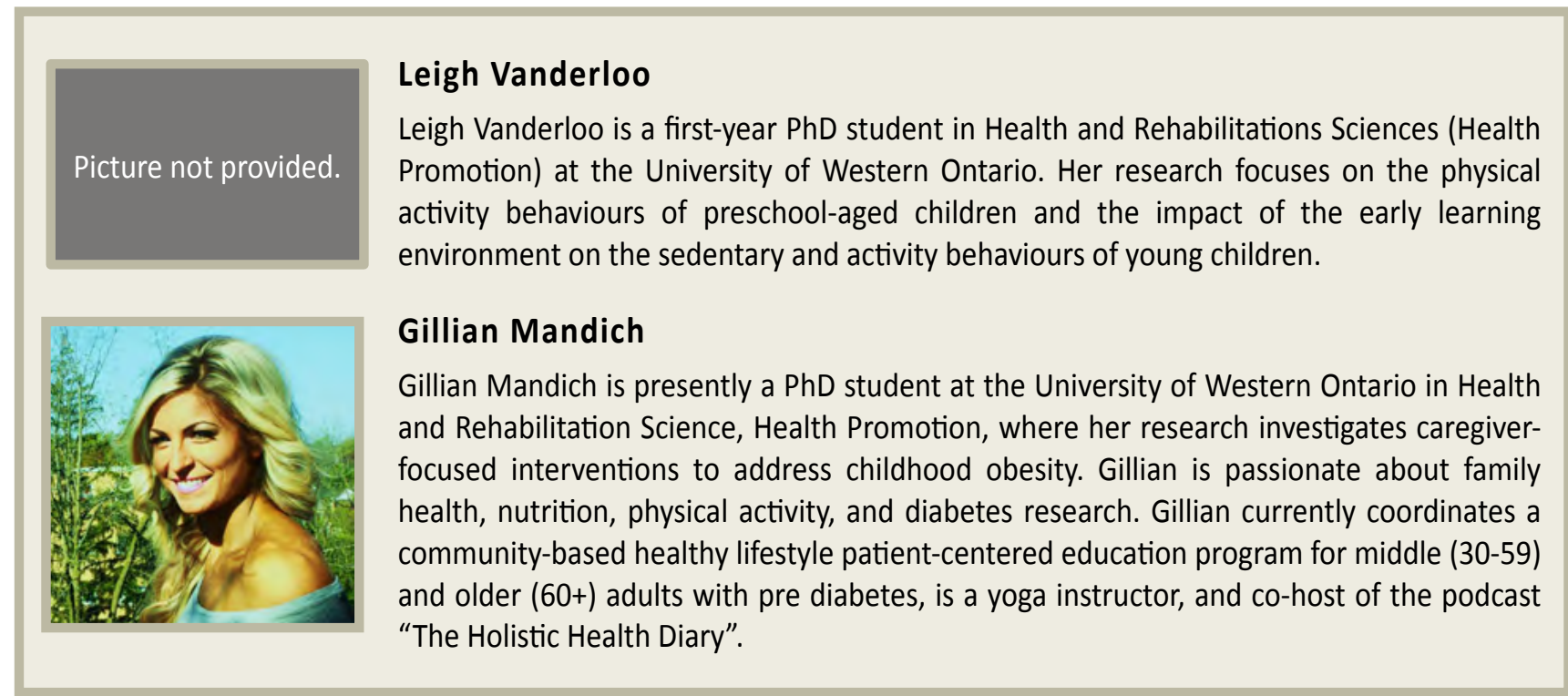

